\title{
Agricultural Support in OECD-Reported Countries from 2000 to 2019
}

\section{Rogério Edivaldo Freitas}

Department of Regional Studies, Institute of Applied Economic Research, Brasília, Brazil

\section{Email address:}

rogerio.freitas@ipea.gov.br

\section{To cite this article:}

Rogério Edivaldo Freitas. Agricultural Support in OECD-Reported Countries from 2000 to 2019. International Journal of Agricultural Economics. Vol. 6, No. 5, 2021, pp. 218-226. doi: 10.11648/j.ijae.20210605.13

Received: September 11, 2021; Accepted: October 14, 2021; Published: October 28, 2021

\begin{abstract}
Agricultural support is one of the main tools used by governments to achieve their domestic goals, especially since the food shortages during and immediately after World War II. However, specific agricultural support programs can affect agricultural production in various ways, and support programs can alter the allocation of natural resources domestically and abroad. In this study, we measured agricultural support in OECD-reported countries during the period 2000-2019 using Spearman's correlation coefficient, time trend analysis and clustering procedures. Data from Organization for Economic Co-operation and Development (OECD) from 2000 to 2019 were employed, specifically the Producer Support Estimate (PSE) and Consumer Support Estimate (CSE). We compared the results of two agglomerative clustering methods and identified groups of similar countries on the basis of their consumer support and producer support estimates behavior during the period studied. Some countries, such as Switzerland, South Korea, Turkey and Canada, displayed specific support behavior, while other groups of countries shared similarities such as China, Indonesia and the Philippines; the European Union, Japan and Norway; and Brazil, South Africa and Chile. Policies implications are discussed and further research is recommended, including analyses of top-down geographical unities, crop-specific programs, and the effects of the COVID-19 pandemic on agricultural support worldwide, as more data becomes available.
\end{abstract}

Keywords: Agricultural Support, OECD-Reported Countries, Spearman's Correlation Coefficient, Clustering

\section{Introduction}

Agricultural subsidies have always been a contentious issue in multilateral trade negotiations. During several General Agreement on Tariffs and Trade rounds, discussions on agricultural products have been set aside, and some attempts to better align agricultural subsidies were deferred.

During the Uruguay Round (1986-1994) there was a concerted effort to improve the rules concerning export and domestic subsidies related to agricultural products and foodstuffs, and a decision was made to try to reduce them gradually.

The Doha Round, from 2000 onward, saw progress in implementing that decision, and agricultural subsidies have declined over the last two decades. However, there have been varying degrees of movement according to each country's profile in terms of agricultural production and commercialization.

Lower levels of agricultural subsidies imposed by significant players such as the US, the European Union (EU) and China are crucial in minimizing their impact on agricultural markets worldwide and generating more favorable conditions and market-oriented prices for agricultural producers in developing countries.

In this study, we analyze changes in agricultural support levels in OECD-reported countries from 2000 to 2019 and identify groups of countries displaying similarities in their approach for reducing subsidies. The rest of the paper is organized as follows: section 2 discusses agricultural support, section 3 presents the methodology and database used, section 4 presents the results, discussion and policy implications, and section 5 ends the article with conclusions.

\section{Agricultural Support}

Agricultural support is one of the main tools used by governments to achieve their domestic goals, especially since the food shortages during and immediately after World War II. Their support can be examined in terms of its impact on food production and commercialization, its main programs, or its 
changing goals and profiles over time.

Specific agricultural support programs can affect agricultural production in various ways. Shi, Wu and Olen argue they can affect harvested acreages and crop fields by influencing producers' decisions on land allocation and input use [1]. For Yu and Sumner they can also affect farmers' investments by reducing risk and providing subsidies, especially when risky crop investments are involved [2]. Equally, according to Wise these support programs sometimes result in the overproduction of key crops [3].

In addition, support programs can alter the allocation of natural resources. Kirwan noted that farmers who rent the land they cultivate capture $75 \%$ of the subsidy, leaving $25 \%$ for landowners, and the share captured by landowners increases with local measures of competitiveness in the farmland rental market [4]. Moreover, according to Hopewell agricultural subsidies depress global prices and undermine the competitiveness and livelihoods of poor farmers, and thus have long been seen as a symbol of the injustice of the trading system [5].

Conforming to Hailu and Poon even when agricultural policies are intended to enhance productivity and competitiveness, there is evidence of heterogeneity in production efficiency across farms [6], which can result in a negative correlation between production efficiency and program payments.

Distinct support programs produce different effects. For example, as stated in Esposti, in decoupled programs the farm response depends on the support levels [7] which relies upon the specific country and crop analyzed. Graubner found that decoupled direct payments are a major agricultural policy tool used to support farm income, and while theoretical models commonly predict that most of the payments transfer to land prices, empirical evidence shows that this rarely occurs [8].

For the Japanese context, for example, Takayama, Hashizume and Nakatani reported that direct payments, which take a unique form in Japan, are made to rural communities with sloping and less favored farmland [9].

Globally, conforming to Hirsch and Oberhofer agricultural support levels are at a crossroads, with lower levels in OECD countries and increasing support for agricultural producers in emerging economies observed over recent decades [10]. In particular, since the subprime crisis in 2008 and the subsequent proliferation of bilateral trade agreements, multilateral trade negotiations have lacked effectiveness.

Thus, there is now a challenge and an opportunity to create a more market-oriented agri-environmental international food market. Ferguson and Gars noted that there is room for improvement in the trade as a mechanism for coping with food production volatility [11]; and, as reported by Bareille and Zavalloni, under a policy of partial decentralization, national governments are the most suitably placed to develop appropriate agri-environmental policies [12].

Two of the main tools used to measure subsidy levels are the Trade Restrictiveness Index and OECD indicators, particularly the producer support estimate (PSE). Surry and Rude noted that Trade Restrictiveness Index-based approaches produce higher and more variable indices than the OECD's PSE, which measures policy-related transfers as a share of gross farm receipts [13].

Erjavec and Lovec found that over time the focus of the EU's common agricultural policy (CAP) research has shifted from market distortions to international trade and budgetary decision-making frameworks, as well as broader societal issues, such as food security, the environment, and sustainable development [14].

This change of focus is coupled with the increasing prominence of sustainability-related questions regarding agricultural activities and their externalities, both domestically and globally. In this context, Louhichi et al. found that although the proportions of farms and the utilized agricultural area (UAA) subject to CAP greening were sizeable (55 percent of all farms and 86 percent of the UAA) at the EU-27 level, the reallocated area as a result of CAP greening represented only 4.5 percent of the UAA [15].

The CAP is such an important and established element of the EU's planning strategy that it also produces spillovers in non-farm employment. Conforming to Rizov, Davidova and Bailey, although the magnitude of the effect is small, it is economically significant [16]. Garrone et al. noted that the EU's CAP subsidies increased agricultural labor productivity growth on average, but this aggregate effect hid heterogeneity in terms of the effects of different types of subsidies [17].

The EU's agricultural support structure was also investigated by Neuenfeldt et al, who found that it explained approximately $36 \%$ of EU farm structure variations across regions and time, followed by natural conditions (16\%), agricultural prices $(14 \%)$, macroeconomic variables $(9 \%)$, subsidies $(7 \%)$, population $(6 \%)$, and agricultural income $(6 \%)$ [18].

Beyond its impacts on prices and short-term variables, the CAP affects the adoption of technology concerning crops and farms. For example, according to Boussemart et al., on some French farms, the CAP-driven technology adoption process is related to the type of payments (coupled or decoupled) granted to a selection of farms [19].

About the US, Fields noted that since the Great Depression US farmers had been the beneficiaries of a medley of subsidies and support programs designed to stabilize crop prices, keep farmers farming, and provide families in the US with affordable and reliable food supply [20].

According to $\mathrm{Wu}$, Goodwin and Coble this effort has sometimes produced side effects, such as the presence of moral hazards related to the US crop insurance program [21]. This study found that the likelihood of prevented planting claims increased as the expected market price decreased or as fertilizer costs increased for corn and soybeans in the Prairie Pothole Region and sorghum and cotton in all states.

Concurrently, the situation in China has changed over the last two decades. Hopewell noted that China has emerged as the world's largest provider of subsidies, profoundly transforming global politics and multilateral negotiations regarding agricultural subsidies, as these now primarily center on the conflict between the US and China [5].

Specific agricultural sectors, such as China's dairy industry, warrant detailed examination. Chen and $\mathrm{Yu}$ noted that this sector had undergone consolidation with the support of the 
government, mainly to improve food safety, confirming that subsidies are one of the tools that governments can use to shape a concentrated market with the dual goals of reducing regulatory costs and enhancing quality control [22].

Given international concerns about the COVID-19 pandemic and its consequences, there is no clear future pathway for agricultural support measures, as countries are likely to face different challenges. Notwithstanding this uncertainty, as stated in Kerr, it has been suggested that once the COVID-19 crisis has passed, various governments may wish to strengthen the institutions that govern international trade on the basis of what has been learned regarding the international food system's resilience [23].

However, the opposite could also occur; due to their COVID-19 experiences, governments may prioritize domestic supply in preference to foreign sources and reverse the impacts of globalization on their food supply systems. At the same time, as pointed out by Barichello, with a deep recession forecast for the global economy, international trade can be expected to fall more steeply, accompanied by increased import restrictions, which might mean more costly inspections, stricter food safety regulations, and protectionist measures aimed at favoring domestic producers [24].

\section{Methodology and Data Source}

We used Organization for Economic Co-operation and Development (OECD) annual data from 2000 to 2019 relating to the EU, South Africa, Argentina, Australia, Brazil, Canada, Chile, China, Colombia, South Korea, Costa Rica, the United States, the Philippines, India, Indonesia, Iceland, Israel, Japan, Kazakhstan, Mexico, Norway, New Zealand, Russia, Switzerland, Turkey, Ukraine, and Vietnam $[25,26]^{1}$. Two measures of agricultural support were used, namely, the Producer Support Estimate (PSE) and the Consumer Support Estimate (CSE).

The evaluation method involves three steps. First, the Spearman correlation coefficient is used to verify PSE and CSE trends over time. Second, a linear time trend is estimated for those countries where the Spearman correlation coefficient identifies a trend over time. Third, cluster analysis is used to identify groups of countries based on the estimated trends over time and similar countries based on the level of agricultural support provided during the period 2000-2019.

\subsection{Spearman Correlation Coefficient}

Conforming the OECD, the PSE indicator estimates the annual monetary value of gross transfers from consumers and taxpayers to agricultural producers, measured at the farm-gate level, arising from policy measures that support agriculture, regardless of their nature, objectives or impacts on farm production or income. Complementing this indicator, the CSE reflects the annual monetary value of gross transfers to consumers of agricultural commodities, measured at the farm gate level, arising from policy measures that support

\footnotetext{
${ }^{1}$ Although some of these countries are not associated with the OECD formally, OECD measures PSE and CSE for them.
}

agriculture, regardless of their nature, objectives or impacts on consumption of farm products [26].

The Spearman correlation coefficient was used to evaluate whether there was a trend in either the PSE or the CSE during 2000-2019. According to Conover, and Morettin and Toloi, it is a non-parametric test and does not require the original data to be normally distributed $[27,28]$. Here, it means to calculate the correlation coefficient between the ranks of the subsidy levels (S) and their corresponding time frame. The Spearman correlation coefficient is calculated as follows:

$$
\rho=1-(6 . d) /\left(\mathrm{N} .\left(\mathrm{N}^{\wedge} 2-1\right)\right)
$$

where

$$
\mathrm{d}=\sum_{1}^{\mathrm{T}}\left[\mathrm{R}_{\mathrm{t}}-\mathrm{t}\right]^{2}
$$

$\mathrm{R}_{\mathrm{t}}$ is the variable rank for the respective time moment and $\mathrm{t}=1,2,3, \ldots, \mathrm{T}$ is the natural rank for the different time moments. The underlying concept is that the greater the difference between $R_{t}$ and $t$, the higher the probability of rejecting the null time trend.

\subsection{Time Trend Analysis}

If the Spearman correlation coefficient test identifies a non-null time trend, a time trend is estimated. As a first step, the linear ${ }^{2}$ approach is used, that is, the time (T) is the explanatory variable for the subsidy S (PSE or CSE) based on equation 3 , where the compound $u_{i}$ is assumed to represent the classical hypothesis regarding the residual in linear regression models:

$$
S_{t}=\beta_{0}+\beta_{1} \cdot T+u_{i}
$$

Barreto and Howland pointed out that the model decomposes the total sum of squares (TSS) into the explained sum of squares (ESS) and the residual sum of squares (RSS) [29], as follows:

$$
\begin{gathered}
T S S=E S S+R S S=\sum_{t=1}^{T}\left(S_{t}-S_{m}\right)^{2}=\sum_{t=1}^{T}\left(S_{e s t}-\right. \\
\left.S_{m}\right)^{2}+\sum_{t=1}^{T}\left(e_{e s t}\right)^{2}
\end{gathered}
$$

where $S_{m}$ is the average measure of subsidy $S_{t}, S_{\text {est }}$ is the estimated value for each data sample, and $e_{e s t}$ is the corresponding residual.

Using the sources of variance and degrees of freedom in each equation term, it is possible to calculate the analysis of variance (see Table 1), whose F-test allows evaluating the statistical significance of the equation 3 coefficients.

Table 1. Analysis of variance.

\begin{tabular}{llll}
\hline Source (A) & $\begin{array}{l}\text { Degrees of } \\
\text { freedom (B) }\end{array}$ & $\begin{array}{l}\text { Mean square } \\
(\mathbf{A}) /(\mathbf{B})\end{array}$ & F-test (F) \\
\hline ESS & 1 & $\mathrm{MSE}=\mathrm{ESS} / 1$ & $\mathrm{~F}=\mathrm{MSE} / \mathrm{MSR}$ \\
$\mathrm{RSS}$ & $(\mathrm{n}-2)$ & $\mathrm{MSR}=\mathrm{RSS} /(\mathrm{n}-2)$ & \\
TSS & $(\mathrm{n}-1)$ & $\mathrm{TSS} /(\mathrm{n}-1)$ & \\
\hline
\end{tabular}

Source: The author, based on Barreto and Howland [29].

\footnotetext{
${ }^{2}$ Using longer data series, more complex approaches could be adopted, including seasonal terms and a non-linear framework.
} 


\subsection{Cluster Analysis of the Agricultural Support Profile in OECD-Reported Countries}

The third step is cluster analysis. Countries in which a time trend is identified based on the Spearman correlation coefficient as per Sub-section 3.1 and the estimated time trends identified in Sub-section 3.2 are clustered based on either PSE or CSE time trends.

Cluster analysis has been used for more than a century to identify similarities among individual items in a data set. As stated in Driver and Kroeber, and Zubin, and Sokal and Sneath, it has been used in numerous fields, including archaeology [30], psychology and psychiatry [31, 32], and has been applied to taxonomic characteristics [33].

The agglomeration process can be divided into hierarchical and non-hierarchical agglomeration. The former involves a step-by-step procedure to generate the clusters, while the latter uses algorithms to maximize homogeneity within groups without applying a hierarchical process.

Among the hierarchical agglomerative methods used, the most common are the nearest (or single) neighbor linkage method, the further (or complete) neighbor linkage method, and the between (or average) groups linkage method. These methods do not require a pre-defined number of clusters to act as agglomerative centers. Among the non-hierarchical agglomerative methods used, the most common is the k-means procedure, wherein agglomeration centers are defined and used as bases to which individual items are allocated based on their proximity.

Unless stated otherwise, we follow Johnson and Wichern and use the hierarchical agglomerative method to identify clusters. These are then used as inputs to the k-means non-hierarchical agglomerative method [34]. The cluster analysis uses Euclidian distance, with a focus on the single (or nearest) distance. According to Fávero and Belfiore this approach is appropriate when the observations regarding the measured variables display a high level of variability, which is the case for the evaluated data set [35].

Euclidean distance is defined as a function of the $\mathrm{X}$ variables associated with two elements of a group and can be expressed as follows:

$$
d\left(X_{1}, X_{k}\right)=\left[\left(X_{1}-X_{k}\right)\left(X_{1}-X_{k}\right)\right]^{1 / 2}=\left[\sum_{i=1}^{p}\left(X_{i 1}-X_{i k}\right)^{2}\right]^{1 / 2}
$$

where $\mathrm{i}$ represents the variables or characteristics of each sample element and $\mathrm{k}$ represents the number of elements.

The calculations involve two steps. First, the agglomerative hierarchical method is used to identify the number of groups. Then, the number of groups identified is used as an input for the k-means non-hierarchical agglomerative method.

Once the hierarchical agglomerative and k-means non-hierarchical agglomerative methods have been applied, the results can be compared. In addition, conforming to Greene, and Barreto and Howland, it is possible to test for the presence of different averages among the clusters using the $\mathrm{F}$ test approach, based on the following hypothesis [36, 29]:
$\mathrm{H} 0$ : variable (PSE or CSE trend) has the same average for every cluster.

Ha: variable (PSE or CSE trend) has a different average for at least one cluster.

This allows us to perform a clusters check so for the hierarchical agglomerative procedure as for the k-means non-hierarchical agglomerative procedure.

\section{Results and Discussion}

The first results sub-section discusses the Spearman correlation coefficient tests for OECD-reported countries for the period 2000-2019, the second sub-section presents the time trend analysis and the third sub-section discusses the clustering results.

\subsection{Spearman Correlation Coefficient}

Table 2 presents the Spearman correlation coefficient calculations for both PSE and CSE in OECD-reported countries for the 2000-2019 period.

Table 2. Results of Spearman correlation coefficient calculations in OECD-reported countries (2000-2019).

\begin{tabular}{lll}
\hline Country & $\begin{array}{l}\text { PSE Spearman } \\
\text { coefficient }\end{array}$ & $\begin{array}{l}\text { CSE Spearman } \\
\text { coefficient }\end{array}$ \\
\hline European Union & $-0.842 * * *$ & $0.805 * * *$ \\
Canada & $-0.857 * * *$ & $0.614 * * *$ \\
China & $0.803 * * *$ & $-0.783 * * *$ \\
South Korea & $-0.817 * * *$ & $0.773 * * *$ \\
United States & $-0.591 * * *$ & $0.635 * * *$ \\
Japan & $-0.853 * * *$ & $0.827 * * *$ \\
Mexico & $-0.968 * * *$ & $0.758 * * *$ \\
Russia & -0.053 & 0.149 \\
South Africa & $-0.555 * *$ & $0.513 *$ \\
Argentina & -0.307 & 0.230 \\
Australia & $-0.779 * * *$ & $0.750 * * *$ \\
Brazil & $-0.857 * * *$ & $0.785 * * *$ \\
Chile & $-0.835 * * *$ & $0.826 * * *$ \\
Colombia & $-0.627 * * *$ & $0.620 * * *$ \\
Costa Rica & -0.036 & 0.039 \\
Philippines & $0.701 * * *$ & $-0.684 * * *$ \\
India & -0.083 & 0.217 \\
Indonesia & $0.808 * * *$ & $-0.806 * * *$ \\
Iceland & $-0.523 *$ & 0.391 \\
Israel & 0.116 & -0.189 \\
Kazakhstan & -0.093 & $0.565 * *$ \\
Norway & $-0.615 * * *$ & $0.556 * *$ \\
New Zealand & -0.058 & -0.060 \\
Switzerland & $-0.710 * * *$ & $0.794 * * *$ \\
Turkey & $-0.513 *$ & $0.611 * * *$ \\
Ukraine & -0.115 & -0.101 \\
Vietnam & $-0.586 * * *$ & 0.433 \\
\hline & &
\end{tabular}

Source: the author, based on OECD $[25,26]$.

Note: * 5\% significance level, $* * 2 \%$ significance level, $* * * 1 \%$ significance level.

At the $1 \%$ significance level, most OECD-reported countries displayed a trend over time for PSE and CSE estimates during 2000-2019. Vietnam, Ukraine, New Zealand, Kazakhstan, Israel, Iceland, India, Costa Rica, Argentina, and Russia did not display a significant trend for either estimate; 
therefore, they were excluded from the next step.

Remarkably, China, the Philippines, and Indonesia were the only three countries with significant Spearman correlation coefficient values for a positive PSE and a negative CSE.

There are two reasons for this, especially in China. Firstly, particular strategies are associated with China's large population and economic growth in the present century. Chen and $\mathrm{Yu}$ highlighted the strategic profile in its agricultural subsidies [22]. And, at second, concentration support on the producer side detrimentally to the consumer stage. Both reasons mean mainly food security worries associated with their economic performance ${ }^{3}$.

\subsection{Time Trend Analysis}

On the basis of the results obtained in the first step, PSE and CSE trends over time were calculated for Australia, Brazil, Canada, Chile, China, Colombia, the EU, Indonesia, Japan, Mexico, Norway, the Philippines, South Africa, South Korea, Switzerland, Turkey, and the US (see Table 3). These countries include most G20 countries ${ }^{4}$ and almost all the world's leading importers and exporters of food products ${ }^{5}$.

Table 3. PSE and CSE trends over time for OECD-reported countries (20002019).

\begin{tabular}{lll}
\hline Country & PSE time trend & CSE time trend \\
\hline European Union & $-0.778 * * *$ & $0.747 * * *$ \\
Canada & $-0.694 * * *$ & $0.239 * *$ \\
China & $0.546 * * *$ & $-0.501 * * *$ \\
South Korea & $-0.928 * * *$ & $0.714 * * *$ \\
United States & $-0.517 * * *$ & $0.545 * * *$ \\
Japan & $-0.717 * * *$ & $0.622 * * *$ \\
Mexico & $-0.810 * * *$ & $0.714 * * *$ \\
South Africa & $-0.239 * * *$ & $0.214 * *$ \\
Australia & $-0.125 * * *$ & $0.111 * * *$ \\
Brazil & $-0.395 * * *$ & $0.325 * * *$ \\
Colombia & $-0.462 * * *$ & $0.466 * * *$ \\
Chile & $-0.233 * * *$ & $0.402 * * *$ \\
Philippines & $0.590 * * *$ & $-0.537 * * *$ \\
Indonesia & $1.195 * * *$ & $-1.377 * * *$ \\
Norway & $-0.605 * * *$ & $0.683 * * *$ \\
Switzerland & $-1.083 * * *$ & $1.809 * * *$ \\
Turkey & $-0.427 *$ & $0.659 * * *$ \\
\hline
\end{tabular}

Source: the author, based on OECD $[25,26]$.

Note: * $5 \%$ significance level, $* * 2 \%$ significance level, ${ }^{* * *} 1 \%$ significance level.

The results presented in Table 3 suggested that some countries had similar PSE and CSE trends over time. In general, these countries showed PSE and CSE trends over time at the $1 \%$ significance level. With the exception of

\footnotetext{
${ }^{3}$ It can be analyzed in further studies as well as a crop-specific evaluation for the agricultural products most commonly supported by OECD-reported countries.

${ }^{4}$ As reported by OECD it includes Argentina, Australia, Brazil, Canada, China, France, Germany, India, Indonesia, Italy, Japan, Mexico, Russia, Saudi Arabia, South Africa, South Korea, Turkey, the United Kingdom, the United States, and Spain [37].

${ }^{5}$ World Trade Organization (WTO) reported that the top food product exporters were the European Union, the United States, Brazil, China, Canada, Argentina, Mexico, Thailand, India, and Indonesia, and the top food product importers were the European Union, the United States, China, Japan, the United Kingdom, Canada, South Korea, Russia, Hong Kong, and Mexico [38]
}

China, Indonesia, and the Philippines, they showed a negative PSE trend and a positive CSE trend over time. The three exceptions, China, the Philippines, and Indonesia, displayed a positive PSE trend over time of 0.546, 0.590 and 1.195 , respectively, reflecting the increased support for producers in those countries.

The most negative PSE trends over time were displayed by Switzerland, South Korea, Mexico, and the EU, with values of $-1.083,-0.928,-0.810$, and -0.778 , respectively. Erjavec and Lovec and Neuenfeldt et al. have also studies confirming a shift in the EU's agricultural support in recent years $[14,18]$.

The strongest CSE trends over time were displayed by Switzerland, Indonesia, the EU, South Korea, and Mexico, with values of $1.809,-1.377,0.747,0.714$, and 0.714 , respectively. Once again, China, the Philippines, and Indonesia were exceptions to the general trend of reduced support for producers and increased support for consumers. In the case of China, Hopewell and Chen and Yu have also similar findings, highlighting China's increasing role in terms of worldwide agricultural producer support [5, 22].

\subsection{Cluster Analysis of Agricultural Support in OECD-Reported Countries}

Here, we discuss various dispersion measures used to prepare the clustering procedure before choosing the hierarchical agglomerative method. The single linkage method is suitable when observations are distant (dispersed) from each other. Conversely, the complete linkage method is appropriate when the dispersion is small, i.e., when observations are near each other.

Table 4 shows the dispersion values for OECD-reported countries for 2000-2008 and 2009-2019, and the overall period 2000-2019. It presents the range (R), average (Av), standard deviation (SD), and coefficient of variation (CV) for all countries.

The first sub-period corresponds to data obtained prior to the subprime crisis in 2008, while the second sub-period corresponds to data obtained following the subprime crisis. The subprime crisis had its origins in the US real estate market before spreading to the financial and economic sectors worldwide.

Table 4. PSE and CSE average and dispersion values for OECD-reported countries.

\begin{tabular}{llll}
\hline \multirow{2}{*}{ Country } & \multicolumn{3}{l}{ PSE Average } \\
\cline { 2 - 4 } & $\mathbf{2 0 0 0 - 2 0 0 8}$ & $\mathbf{2 0 0 9 - 2 0 1 9}$ & $\mathbf{2 0 0 0 - 2 0 1 9}$ \\
\hline European Union & 28.229 & 19.365 & 23.354 \\
Canada & 17.592 & 10.448 & 13.663 \\
China & 7.453 & 13.589 & 10.828 \\
South Korea & 58.409 & 48.366 & 52.886 \\
United States & 14.680 & 8.927 & 11.516 \\
Japan & 49.546 & 43.313 & 46.118 \\
Mexico & 18.540 & 10.725 & 14.242 \\
South Africa & 6.910 & 3.435 & 4.999 \\
Australia & 3.982 & 2.357 & 3.089 \\
Brazil & 7.587 & 3.960 & 5.592 \\
Colombia & 19.536 & 16.856 & 18.062 \\
Chile & 5.077 & 2.885 & 3.872 \\
Philippines & 18.338 & 25.099 & 22.057 \\
Indonesia & 7.058 & 20.723 & 14.574 \\
Norway & 65.068 & 59.098 & 61.785 \\
\hline
\end{tabular}




\begin{tabular}{|c|c|c|c|}
\hline \multirow{2}{*}{ Country } & \multicolumn{3}{|c|}{ PSE Average } \\
\hline & 2000-2008 & 2009-2019 & 2000-2019 \\
\hline Switzerland & 62.018 & 49.863 & 55.333 \\
\hline Turkey & 27.162 & 23.479 & 25.137 \\
\hline (R) (all countries) & 61.086 & 56.741 & 58.696 \\
\hline$[\mathrm{R} / \mathrm{Av}]$ & 24.540 & 21.323 & 22.771 \\
\hline (Av) (all countries) & 2.489 & 2.661 & 2.578 \\
\hline SD (all countries) & 21.039 & 18.139 & 19.220 \\
\hline CV (all countries) & 0.857 & 0.851 & 0.844 \\
\hline \multirow{2}{*}{ Country } & \multicolumn{3}{|c|}{ CSE Average } \\
\hline & 2000-2008 & 2009-2019 & 2000-2019 \\
\hline European Union & -12.570 & -3.872 & -7.786 \\
\hline Canada & -11.646 & -10.097 & -10.794 \\
\hline China & -4.139 & -10.268 & -7.510 \\
\hline South Korea & -52.292 & -45.172 & -48.376 \\
\hline United States & 7.626 & 14.409 & 11.357 \\
\hline Japan & -43.273 & -37.464 & -40.078 \\
\hline Mexico & -8.988 & -1.810 & -5.040 \\
\hline South Africa & -5.167 & -2.209 & -3.540 \\
\hline Australia & -1.388 & -0.134 & -0.698 \\
\hline Brazil & -3.464 & -0.436 & -1.799 \\
\hline Colombia & -23.486 & -20.438 & -21.810 \\
\hline Chile & -4.477 & -0.424 & -2.248 \\
\hline Philippines & -18.704 & -25.088 & -22.216 \\
\hline Indonesia & -8.127 & -24.415 & -17.085 \\
\hline Norway & -46.596 & -39.946 & -42.939 \\
\hline Switzerland & -51.864 & -31.151 & -40.472 \\
\hline Turkey & -25.487 & -20.006 & -22.473 \\
\hline (R) (all countries) & 59.918 & 59.581 & 59.733 \\
\hline$[\mathrm{R} / \mathrm{Av}]$ & -18.473 & -15.207 & -16.677 \\
\hline (Av) (all countries) & -3.244 & -3.918 & -3.582 \\
\hline SD (all countries) & 19.030 & 16.883 & 17.456 \\
\hline CV (all countries) & -1.030 & -1.110 & -1.047 \\
\hline
\end{tabular}

Source: the author, based OECD $[25,26]$.

Regarding the 2000-2008 and 2009-2019 sub-periods, there are four notable observations from Table 3. First, the PSE standard deviation is $85 \%$ of the average PSE for both sub-periods. Second, the CSE coefficient of variation is greater than 1 for both sub-periods. Third, in the 2000-2008 sub-period, Norway's and Switzerland's PSE are beyond the PSE range; that is, they are outliers ${ }^{6}$. Fourth, Norway is also an outlier $^{7}$ in terms of its PSE in the 2009-2019 sub-period.

In addition, for the 2000-2019 period, the PSE range was 22.8 times the PSE average and the PSE coefficient of variation was $84 \%$, while the CSE range was almost 16.7 times (module value) the CSE average and the CSE coefficient of variation was greater than 1 (1.047, module value), indicating a high level of variability.

Thus, because the data were increasingly dispersed over time, the single linkage method was selected as the hierarchical agglomerative method.

\footnotetext{
${ }^{6}$ Norway's and Switzerland's PSE surpassed their respective upper bounds, which are given by $\left(\mathrm{J} 3+1.5^{*} \mathrm{Dj}\right)$, where $\mathrm{J} 3$ is the third quartile of the PSE distribution for $2000-2008, \mathrm{Dj}$ is the difference between $\mathrm{J} 3$ and $\mathrm{J} 1$, and $\mathrm{J} 1$ is the first quartile of the PSE distribution for 2000-2008.

${ }^{7}$ Norway's PSE surpassed the upper bound, which is given by $(\mathrm{J} 3+1.5 * \mathrm{Dj})$, where $\mathrm{J} 3$ is the third quartile of the PSE distribution for 2009-2019, Dj is the difference between $\mathrm{J} 3$ and $\mathrm{J} 1$, and $\mathrm{J} 1$ is the first quartile of the PSE distribution for 20092019.
}

\subsubsection{Clustering Analysis Procedure}

The clustering analysis was based on the time trends obtained in the first two methodological steps, and the single linkage hierarchical agglomerative method was used to create a dendrogram according to Figure 1, which is a branching diagram representing a hierarchy of categories based on the degree of similarity or number of shared characteristics and very commonly used in clustering analysis ${ }^{8}$.

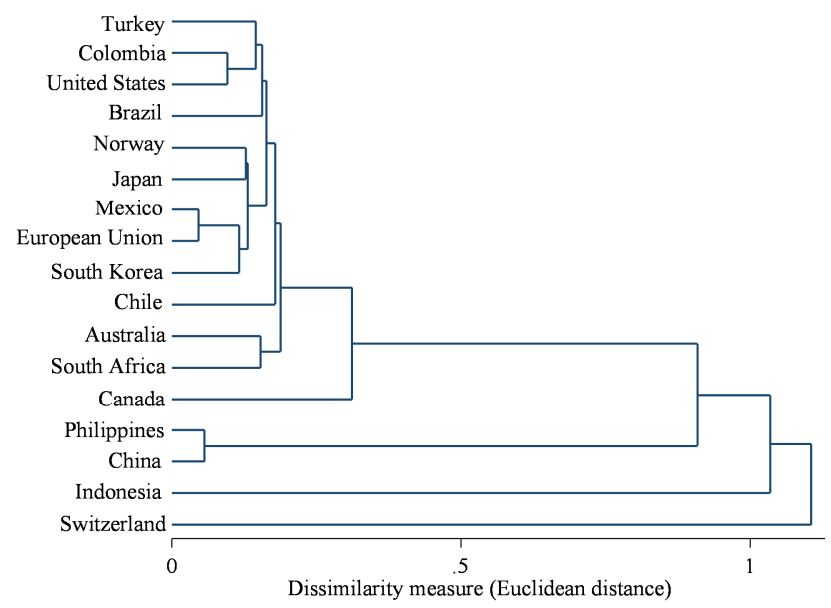

Figure 1. Dendrogram for OECD-reported countries based on PSE and CSE trends over time (2000-2019).

By visual inspection, Figure 1 suggests that there are six subgroups of countries based on similarities in their PSE and CSE trends during 2000-2019. These subgroups arise from the jumps in the dissimilarity measures (Euclidean distance) presented on the $\mathrm{X}$-axis. The subgroups are Turkey, Colombia, the US and Brazil; Norway, Japan, Mexico, the EU and South Korea; Chile, Australia and South Africa; Canada; the Philippines and China; and Indonesia and Switzerland.

Additionally, if $\mathrm{k}=6$, the $\mathrm{k}$-means non-hierarchical agglomerative method can also be used. Therefore, it is possible to compare the results obtained using these two methods and analyze them. So, Table 5 shows the results for the single linkage hierarchical agglomerative method (cluster) and the k-means non-hierarchical agglomerative method when $\mathrm{k}=6$, as shown in Figure 1.

Table 5. OECD-reported country clusters using the hierarchical and k-means non-hierarchical agglomerative methods (2000-2019).

\begin{tabular}{llll}
\hline K-means & & Hierarchical (cluster) \\
\hline Country & Group & Country & Group \\
\hline Switzerland & 1 & Switzerland & 1 \\
Australia & 2 & Indonesia & 2 \\
Brazil & 2 & China & 3 \\
Canada & 2 & Philippines & 3 \\
South Africa & 2 & Canada & 4 \\
China & 3 & Australia & 5 \\
Indonesia & 3 & South Africa & 5 \\
Philippines & 3 & Brazil & 6 \\
European Union & 4 & Chile & 6 \\
Mexico & 4 & Colombia & 6 \\
\hline
\end{tabular}

${ }^{8}$ As reported by Stata-Statistics/Data Analysis, the Stata procedures were used for both the hierarchical cluster analysis and the k-means cluster analyses [39]. 


\begin{tabular}{llll}
\hline K-means & & \multicolumn{2}{l}{ Hierarchical (cluster) } \\
\hline Country & Group & Country & Group \\
\hline South Korea & 4 & European Union & 6 \\
Chile & 5 & Japan & 6 \\
Colombia & 5 & Mexico & 6 \\
Turkey & 5 & Norway & 6 \\
United States & 5 & South Korea & 6 \\
Japan & 6 & Turkey & 6 \\
Norway & 6 & United States & 6 \\
\hline
\end{tabular}

Source: the author, based on OECD $[25,26]$.

The results presented in Table 5 were checked to verify whether the clusters displayed different means for their PSE trends and their CSE trends. Table 6 shows the results. Since the critical $F$ test value is 4.69 at the $1 \%$ significance level, they confirmed that the clusters displayed different means.

Table 6. Results of F tests for the country clusters for PSE and CSE trends (2000-2019).

\begin{tabular}{lll}
\hline Procedure & PSE & CSE \\
\hline Hierarchical procedure (cluster) & $26.990 * * *$ & $80.333 * * *$ \\
Non-hierarchical procedure (k-means) & $22.696 * * *$ & $27.475 * * *$ \\
\hline
\end{tabular}

Source: the author, based on $\operatorname{OECD}[25,26]$. Note: *** $1 \%$ significance level.

Results presented in Table 4 showed Switzerland as outlier; this was confirmed by the results presented in Table 5, which showed that Switzerland has a unique profile of declining producer support and increasing consumer support. South Africa and Australia belonged to the same cluster, regardless of the method used, and the same applied to China and the Philippines.

The hierarchical method identified a single cluster of ten elements, that is, Brazil, Chile, Colombia, European Union, Japan, Mexico, Norway, South Korea, Turkey and the United States. Thus, the k-means method seems to be more suitable, as it identified more distributed countries based on their PSE and CSE trends over time. Applying the k-means method, European Union and Brazil, and Colombia and Norway belong to different clusters, which makes sense because all those countries have very different priorities and strategies for their agricultural sectors.

China, Indonesia, and the Philippines were clustered together using the k-means approach, which follows table 3 and seems logical because they are populous countries and must develop appropriate policies on this basis. In the case of China, according to Fukase and Martin, only continuous growth in agricultural productivity will enable China to rely solely on its domestic food supply [40]. This also applies, mutatis mutandis, to other populous countries in Asia, such as Indonesia and the Philippines.

In addition, conforming to WTO it is important to discuss the results for other big agricultural producers and importers, such as the US and the EU [38]. In both these cases, the results show declining producer support and increasing consumer support, with more pronounced trends in the EU. Erjavec and Lovec, and Louhichi et al, had already reported this finding in relation to the CAP $[14,15]$.

In terms of the bigger picture, producer support has declined, and consumer support has increased over the last two decades except in China, the Philippines and Indonesia. In some countries, this trend has been significant (e.g., Switzerland and South Korea), while in others it has been either moderate (e.g., the EU, Japan and Norway) or slight (e.g., Brazil, South Africa, Australia and Chile).

Some countries, such as Canada and Turkey, present a puzzle in that the intensity of the decrease/increase in producer/consumer support. Future research should address this issue, as well as undertaking a more detailed evaluation of the types of support that have been provided, for example, crop-specific mechanisms, and particular sectors, such as the dairy and meat sectors in China, the dairy and poultry sectors in the EU, and the cereals sector in the US.

Finally, the findings of this study might change significantly in the future due to the COVID-19 pandemic. Given the unpredictable impact of the pandemic on long-term food consumption habits and concerns about food security, the global agricultural support landscape can experience significant changes.

\subsubsection{Policy Implications}

The results show distinct paths of agricultural support in developed and emerging countries. Especially for big Asian countries, there is a clear emphasis on supporting the producers and charging the consumers. The developed countries, in contrast, have shown a transition from producer support to consumer support, sometimes in line with multilateral arrangements established from General Agreement on Tariffs and Trade (GATT) rounds on. Conforming to Wise, these movements are not by chance, but they derive from strategic concerns and sector pressures inside each country [3].

In terms of country analysis, Hopewell argued that there is space for possible growing tensions between the US and China in the trade arena [5], and their kind of agricultural support is an input of these tensions. About the EU, according to Bareille and Zavalloni it seems to head towards sustainability and specific programs [12], which can deep the process of converting producer support into consumer support. In counterpart, as stated in Louhichi et al. the EU also reinforces the programs for specific crops or regions [15] inside the EU countries.

In such a context, a concurrent phenomenon that cannot be forgotten is the recent strategic change by major players from multilateral efforts to bilateral or regional agreements. Moreover, for every single country sustainability concerns tend to be central or inevitable for designing agricultural support policies from now on.

These aspects will work to differentiate the countries' groups of similar behavior in terms of agricultural support. Then, some of the identified groups can strengthen their bonds in the near years, which represents a further agenda. Equally, the countries and their corresponding bilateral agreements can reflect on future clustering studies.

Finally, in agreement with Kerr, a new data that will surely impact the agricultural support decisions worldwide is the COVID-19 pandemic and its effects on all countries [23]. However, for a while, it is unpredictable their medium and long-term impacts on changing agricultural policies.

So, from the results discussed in the previous section, 
developing, developed and emerging countries can have a basement for understanding their locus and stage on world agricultural support, a piece of crucial information for them during bilateral or multilateral negotiations.

\section{Conclusion}

Countries' level of agricultural support has a significant impact on food production and commercialization, and support programs have changed over recent decades. This study aimed to measure trends in agricultural support levels in OECD-reported countries from 2000 to 2019 and identify similarities among various countries.

We used OECD annual data from 2000 to 2019 [25, 26]. The data were analyzed using a three-step process that involved calculating the Spearman correlation coefficient, time trend analysis, and clustering.

Following Spearman correlation coefficient analysis, 17 countries displaying trends were identified, that is, Australia, Brazil, Canada, Chile, China, Colombia, the EU, Indonesia, Japan, Mexico, Norway, the Philippines, South Africa, South Korea, Switzerland, Turkey, and the US. These countries were then examined using time trend analysis and clustering techniques.

The results showed that in PSE analysis, the two outliers were Switzerland and Norway. In addition, some countries had similar PSE and CSE trends. First, China, Indonesia, and the Philippines were the only countries with positive PSE and negative CSE trends. Second, Switzerland, South Korea, the EU, and Mexico displayed highly negative PSE trends and positive CSE trends, while Turkey, the US, Norway, and Colombia displayed moderately negative PSE trends and positive CSE trends. Finally, Brazil and Chile displayed mildly negative PSE trends and positive CSE trends.

These groups of countries can be specifically evaluated in further developments of this study. It could detect homogeneous designs of agricultural support for the countries inside each group.

Switzerland displayed a unique profile, that is, a very expressive declining producer support and increasing consumer support. South Africa and Australia belonged to the same cluster, regardless of the clustering method used, as did China and the Philippines.

The k-means non-hierarchical clustering method seemed to be more appropriate than the hierarchical method, as it identified more diversified clusters based on PSE and CSE trends. For example, using the k-means method, the EU, Brazil, Colombia, and Norway belonged to different clusters, reflecting the different priorities and strategies of their agricultural sectors. At the same time, China, Indonesia, and the Philippines were clustered together using the k-means approach, which seems logical as they are all populous countries.

Overall, results showed that producer support has declined, and consumer support has increased over the last two decades in all countries, except in China, the Philippines and Indonesia. Based on these findings, these three countries also could be an object of further analyses, mainly those designed for monitoring changes in their agricultural policies.

Countries such as Canada and Turkey should be studied in more depth in the future because the intensity of the decrease/increase in producer/consumer support differs remarkably. There should also be further research at the crop-specific level, for example, analysis of approaches including top-down crop-specific programs (soybeans, corn, poultry, or dairy products) in key countries (e.g., Japan, China, the EU, and the US).

Finally, the potential effects of the COVID-19 pandemic should not be overlooked in future research. The pandemic is likely to have impacted long-term food consumption habits, and thus agricultural support worldwide can face substantial changes, particularly if associated with further reductions in multilateral trade negotiations.

\section{Acknowledgements}

We thank Geoff Whyte, MBA, from Edanz (https://www.edanz.com/ac) for editing a draft of this manuscript.

\section{References}

[1] Shi, J., Wu, J., Olen, B., (2019). Assessing effects of federal crop insurance supply on acreage and yield of specialty crops. Canadian Journal of Agricultural Economics, 68 (1): 65-82. https://doi.org/10.1111/cjag.12211.

[2] Yu, J., Sumner, D. A., (2018). Effects of subsidized crop insurance on crop choices. Agricultural Economics, 49 (4): 533-545. https://doi.org/10.1111/agec.12434.

[3] Wise, T. A., (2004). The Paradox of Agricultural Subsidies: Measurement Issues, Agricultural Dumping, and Policy Reform. Global Development and Environment Institute. Working Paper 04-02. Available at: https://sites.tufts.edu/gdae/files/2020/03/04-02AgSubsidies.pdf

[4] Kirwan, B. E., (2009). The incidence of U.S. agricultural subsidies on farmland rental rates. Journal of Political Economy, 117 (1): 138-164. https://doi.org/10.1086/598688.

[5] Hopewell, K., (2019). US-China conflict in global trade governance: the new politics of agricultural subsidies at the WTO. Review of International Political Economy, 26 (2): 207-231. https://doi.org/10.1080/09692290.2018.1560352.

[6] Hailu, G., Poon, K., (2017). Do farm support programs reward production inefficiency? Canadian Journal of Agricultural Economics, 65 (4): 567-589. https://doi.org/10.1111/cjag.12150.

[7] Esposti, R., (2017). The empirics of decoupling: Alternative estimation approaches of the farm-level production response. European Review of Agricultural Economics, 44 (3): 499-537. https://doi.org/10.1093/erae/jbw021.

[8] Graubner, M., (2018). Lost in space? The effect of direct payments on land rental prices. European Review of Agricultural Economics, 45 (2): 143-171. https://doi.org/10.1093/erae/jbx027.

[9] Takayama, T., Hashizume, N., Nakatani, T., (2020). Impact of direct payments on agricultural land use in less-favoured areas: Evidence from Japan. European Review of Agricultural Economics, 47 (1): 157-177. https://doi.org/10.1093/erae/jbz008. 
[10] Hirsch, C., Oberhofer, H., (2020). Bilateral trade agreements and price distortions in agricultural markets. European Review of Agricultural Economics, 47 (3): 1009-1044. https://doi.org/10.1093/erae/jbz004.

[11] Ferguson, S. M., Gars, J., (2020). Measuring the impact of agricultural production shocks on international trade flows. European Review of Agricultural Economics, 47 (3): 1094 1132. https://doi.org/10.1093/erae/jbz013.

[12] Bareille, F., Zavalloni, M., (2020). Decentralization of agri-environmental policy design. European Review of Agricultural Economics, $47 \quad$ (4): 1502-1530. https://doi.org/10.1093/erae/jbz049.

[13] Surry, Y., Rude, J., (2019). Agriculture trade restrictiveness in Canada: How important are the cross effects? Canadian Journal of Agricultural Economics, 67 (4): 433-448. https://doi.org/10.1111/cjag.12204.

[14] Erjavec, E., Lovec, M., (2017). Research of European Union's Common Agricultural Policy: disciplinary boundaries and beyond. European Review of Agricultural Economics, 44 (4): 732-754. https://doi.org/10.1093/erae/jbx008.

[15] Louhichi, K., Ciaian, P., Espinosa, M., Perni, A., Paloma, S. G., (2018). Economic impacts of CAP greening: application of an EU-wide individual farm model for CAP analysis (IFM-CAP). European Review of Agricultural Economics, 45 (2): 205-238. https://doi.org/10.1093/erae/jbx029.

[16] Rizov, M., Davidova, S., Bailey, A., (2018). Employment effects of CAP payments in the UK non-farm economy. European Review of Agricultural Economics, 45 (5): 723-748. https://doi.org/10.1093/erae/jby008.

[17] Garrone, M., Emmers, D., Lee, H., Olper, A., Swinnen, J., (2019). Subsidies and agricultural productivity in the EU. $\begin{array}{llll}\text { Agricultural Economics, } 50 & \text { (6): } 803-817 .\end{array}$ https://doi.org/10.1111/agec.12526.

[18] Neuenfeldt, S., Gocht, A., Heckelei, T., Ciaian, P., (2019). Explaining farm structural change in the European agriculture: a novel analytical framework. European Review of Agricultural Economics, $46 \quad$ (5): $713-768$. https://doi.org/10.1093/erae/jby037.

[19] Boussemart, J. P., Henri-Bertrand, L., Leleu, H., Parvulescu, R., (2019). Technical catching-up and decoupled payments in a selection of French farms. European Review of Agricultural Economics, $\quad 46 \quad$ (2): $215-235$. https://doi.org/10.1093/erae/jby023.

[20] Fields, S., (2004). The fat of the land: Do agricultural subsidies foster poor health? Environmental Health $\begin{array}{lll}\text { Perspectives, } & 112 & \text { (14): }\end{array}$ https://doi.org/10.1289/ehp.112-a820.

[21] Wu, S., Goodwin, B. K., Coble, K., (2020). Moral hazard and subsidized crop insurance. Agricultural Economics, 51 (1): 132-142. https://doi.org/10.1111/agec.12545.

[22] Chen, Y., Yu, X., (2019). Do subsidies cause a less competitive milk market in China? Agricultural Economics, 50 (3): 303-314. https://doi.org/10.1111/agec.12485.

[23] Kerr, W. A., (2020). The COVID-19 pandemic and agriculture: Short- and long-run implications for international trade relations. Canadian Journal of Agricultural Economics, 68: 225-229. https://doi.org/10.1111/cjag.12230.
[24] Barichello, R., (2020). The COVID-19 pandemic: Anticipating its effects on Canada's agricultural trade. Canadian Journal of Agricultural Economics, 68: 219-224. https://doi.org/10.1111/cjag.12244.

[25] Organisation for Economic Co-operation and Development (OECD), (2016). OECD'S Producer Support Estimate and Related Indicators of Agricultural Support - Concepts, Calculations, Interpretation and Use (The PSE Manual). Paris: OECD.

[26] Organisation for Economic Co-operation and Development (OECD), (2020). Agricultural policy monitoring and evaluation. Paris: OECD. Access: sept. 2020. Available at: http://www.oecd.org/agriculture/topics/agricultural-policy-mo nitoring-and-evaluation/.

[27] Conover, W. J., (1999). Practical Nonparametric Statistics, second edition. New York: Wiley.

[28] Morettin, P. A., Toloi, C. M. C., (2006). Time Series Analysis. (Análise de Séries Temporais), second edition. São Paulo: Edgard Blücher.

[29] Barreto, H., Howland, F. M., (2006). Introductory Econometrics: Using Monte Carlo Simulation with Microsoft Excel. New York: Cambridge University Press.

[30] Driver, H. E., Kroeber, A. L., (1932). Quantitative expression of cultural relationships. University of California Publications in American Archeology and Ethnology, 31 (4): 211-256.

[31] Zubin, J. A., (1938a). Technique for measuring mindedness. Journal of Abnormal and Social Psychology, 33 (4): 508-516.

[32] Zubin, J. A., (1938b). Socio-biological types and methods for their isolation. Psychiatry: Journal for the Study of Interpersonal Processes, 2: 237-297.

[33] Sokal, R. R., Sneath, P. H. A., (1963). Principles of Numeric Taxonomy. San Francisco: W. H. Freeman and Company.

[34] Johnson, R. A., Wichern, D. W., (2007). Applied Multivariate Statistical Analysis, sixth edition. NJ: Pearson Education, Upper Saddle River.

[35] Fávero, L. P., Belfiore, P., (2020). Data Analysis Handbook (Manual de Análise de Dados). Rio de Janeiro: LTC.

[36] Greene, W. G., (2017). Econometric Analysis. Yorkshire: Pearson.

[37] Organisation for Economic Co-operation and Development (OECD), (2021). Tax Policy and Climate Change IMF/OECD Report for the G20 Finance Ministers and Central Bank Governors. Italy: OECD.

[38] World Trade Organization (WTO), (2020). World Trade Statistical Review 2020. Available at: https://www.wto.org/english/res_e/statis_e/wts2020_e/wts20_t oc_e.htm. Accessed: 28 Oct. 2020.

[39] Stata - Statistics/Data Analysis, (2015). Hierarchical Cluster Analysis and Kmeans and Kmedians Cluster Analysis. College Station, TX: Stata.

[40] Fukase, E., Martin, W., (2016). Who will feed China in the 21 st century? Income growth and food demand and supply in China. Journal of Agricultural Economics, 67 (1): 3-23. https://doi.org/10.1111/1477-9552.12117. 